\title{
Is Symptomatic Long QT Syndrome Associated with Depression in Women and Men?
}

\section{Wesolowska, Karolina}

2017-06

Wesolowska , K, Elovainio , M , Koponen, M , Tuiskula , A M , Hintsanen, M , Keltikangas-Jarvinen , L , Maattanen , I , Swan , H \& Hintsa , T 2017 , ' Is Symptomatic Long QT Syndrome Associated with Depression in Women and Men? ' , Journal of Genetic Counseling , vol. 26 , no. 3 , pp. 491-500 . https://doi.org/10.1007/s10897-016-0004-4

http://hdl.handle.net/10138/237092

https://doi.org/10.1007/s10897-016-0004-4

publishedVersion

Downloaded from Helda, University of Helsinki institutional repository.

This is an electronic reprint of the original article.

This reprint may differ from the original in pagination and typographic detail.

Please cite the original version. 


\title{
Is Symptomatic Long QT Syndrome Associated with Depression in Women and Men?
}

\author{
Karolina Wesolowska $^{1}$ - Marko Elovainio ${ }^{1,2}$ - Mikael Koponen ${ }^{3}$. \\ Annukka M. Tuiskula ${ }^{4}$ - Mirka Hintsanen ${ }^{5}$ - Liisa Keltikangas-Järvinen ${ }^{1}$. \\ Ilmari Määttänen ${ }^{1} \cdot$ Heikki Swan $^{6} \cdot$ Taina Hintsa $^{1}$
}

Received: 10 November 2015 / Accepted: 2 August 2016/Published online: 23 August 2016

(C) National Society of Genetic Counselors, Inc. 2016

\begin{abstract}
We examined whether long QT syndrome (LQTS) mutation carrier status or symptomatic LQTS are associated with depression, and whether there are sex differences in these potential relationships. The sample comprised 782 participants ( $252 \mathrm{men}$ ). Of the 369 genetically defined LQTS mutation carriers, 169 were symptomatic and 200 were asymptomatic. The control group consisted of 413 unaffected relatives. Depression was assessed using the Beck Depression Inventory-II (BDI-II). No association was found for LQTS mutation carrier status with depression. The multinomial logistic regression showed that LQTS mutation carrier men with arrhythmic events scored higher on depression compared with the control group, even when adjusting for age, $\beta$-blockers, antidepressants, and social support $(O R=1.09,95 \% C I[1.02$, $1.15], p=.007)$. The binary logistic regression comparing symptomatic and asymptomatic LQTS mutation carriers showed that symptomatic LQTS was associated with depression in men $(O R=1.10,95 \% C I[1.03,1.19], p=.009)$. The results were unchanged when additionally adjusted for education. These findings suggest that symptomatic LQTS is
\end{abstract}

Karolina Wesołowska

karolina.wesolowska@helsinki.fi

1 Institute of Behavioral Sciences, University of Helsinki, Siltavuorenpenger 1 A, P.O. Box 9, 00014 Helsinki, Finland

2 National Institute for Health and Welfare, Helsinki, Finland

3 Heart and Lung Center, Helsinki University Central Hospital, Helsinki, Finland

4 Department of Medicine, University of Helsinki and Helsinki University Central Hospital, Helsinki, Finland

5 Faculty of Education, University of Oulu, Oulu, Finland

6 Institute of Clinical Medicine, University of Helsinki, Helsinki, Finland associated with depression in men but not in women. Overall, however, depression is more frequent in women than men. Thus, regular screening for depression in LQTS mutation carriers and their unaffected family members can be important.

Keywords Arrhythmia · Depression · Long QT syndrome (LQTS) $\cdot$ Sex differences

\section{Introduction}

Long QT syndrome (LQTS) is a genetic cardiac disorder characterized by delayed ventricular repolarization leading to QTinterval prolongation observed by electrocardiogram (ECG) and an increased vulnerability to arrhythmic events, such as ventricular arrhythmias and sudden cardiac death (Schwartz et al. 1975). Genetic defects in cardiac ion-channel proteins are the fundamental cause of the syndrome. According to a gene possessing mutations, LQTS has been classified into subtypes, of which LQT1, LQT2, and LQT3 are the most common. The first two types result from changes in the potassium channel genes $K C N Q 1$ and $K C N H 2$ (HERG), respectively, while LQT3 is caused by mutations in the gene $S C N 5 A$, encoding the sodium channel (Giudicessi and Ackerman 2013b). The estimated prevalence of this disorder in Finland is 1:250 (Marjamaa et al. 2009), whereas in other populations it is reported to be 1:2000 (Schwartz et al. 2009). A considerable proportion of the Finnish population can be genetically predisposed to ventricular arrhythmias due to four LQTS founder mutations, KCNQ1 G589D, KCNQ1 IVS7$2 \mathrm{~A}>\mathrm{G}(\mathrm{c} .1129-2 \mathrm{~A}>\mathrm{G}), \mathrm{KCNH} 2 \mathrm{~L} 552 \mathrm{~S}$, and $\mathrm{KCNH} 2$ $\mathrm{R} 176 \mathrm{~W}$, that have become enriched in this isolated population (Marjamaa et al. 2009). 
LQTS penetrance, that is, the percentage of individuals with a particular mutation who manifest clinical signs of the disorder, ranges from $25 \%$ (Priori et al. 1999) to $100 \%$ (Viadero et al. 2011) among members of the same family. Furthermore, the syndrome exhibits variable expressivity, which means that the type and severity of arrhythmic events (i.e., symptoms) can vary between individuals carrying the same mutation (Brink et al. 2005). While genetic determinants underlying incomplete penetrance and variable expressivity remain unclear (Giudicessi and Ackerman 2013a), some demographic factors, for instance, male sex in younger patients and female sex in adult patients, have been suggested to be associated with the arrhythmic risk in LQTS (Locati et al. 1998).

Arrhythmic events in LQTS tend to occur under specific conditions in a gene-specific manner (Schwartz et al. 2001). In LQT1, cardiac events are associated particularly with physical activity, while in LQT2, sudden emotional stress (stressful life events or startling auditory stimuli) is a main trigger of arrhythmias. In LQT3, most of the events occur during rest or sleep (Schwartz et al. 2001). The greater probability of experiencing symptoms under one condition does not, however, exclude the possibility of having cardiac events under other circumstances (Schwartz et al. 2001).

Previous research (Burgess et al. 2005; Ciesla and Roberts 2001; Dickens et al. 2002; Dickens et al. 2004) has repeatedly documented that serious physical illness may increase the risk of mental health problems, including depression. Carrying a LQTS-causing mutation can elicit psychological distress (van Langen et al. 2004) that has been associated with depression (Hammen et al. 2009). LQTS mutation carriers have also been shown to have higher temperamental stress proneness (Määttänen et al. 2011, 2013b). Being genetically diagnosed as a LQTS mutation carrier may be associated with depression because mutation carriers can be worried and stressed about the risk of potentially lethal cardiac events (Farnsworth et al. 2006) and/or about the possibility of having passed the mutation to their children (van Langen et al. 2004), or may experience fatigue due to a lower level of physical activity (Berlin et al. 2006) caused by appropriate lifestyle modifications (e.g., avoidance of participation in competitive sports) related to this syndrome (Priori et al. 2013).

LQTS mutation carriers who have experienced cardiac events (reminding them of the actual risk of death) have been shown to be more stressed than mutation carriers without symptoms (Hintsa et al. 2010). They have also reported periodic feelings of extreme fatigue and exhaustion related to the syndrome itself (Andersen et al. 2008). Thus, it is reasonable to assume that mutation carriers with arrhythmias are at a higher risk of depression compared with those without cardiac events. Our previous study (Hintsa et al. 2009) has shown that depressive symptoms (i.e., a lenient tendency for depressive mood) are associated with symptomatic LQTS independently of sex and age. This study, however, did not include dimensions of depression and a measure to screen for depressive disorder, and did not control for social support, medications ( $\beta$-blockers and antidepressants), and education. When studying depression, social support needs to be taken into account since it has been linked to depression (Huffman et al. 2013; Paykel 1994). Furthermore, social support has been suggested as protecting against pathogenic effects of stressful life events (Paykel 1994). Previous research (Hintsa et al. 2016) has reported that encountering stressful life events is associated with an increased risk of depressive mood in LQTS mutation carriers with arrhythmic events.

Generally, the association between depression and cardiovascular disease has been shown to be stronger in women and women diagnosed with this illness have scored higher on depression compared with men (Moller-Leimkuhler 2007). The prevalence of major depression is also two-times greater in female than male coronary artery disease patients (Shanmugasegaram et al. 2012). Therefore, sex differences in the potential associations of LQTS mutation carrier status or symptomatic LQTS with depression can be assumed. Moreover, because younger age, low education (Huffman et al. 2013), and $\beta$-blockers (Verbeek et al. 2011) may increase the risk of depression, their influence on the hypothesized relationships can also be expected.

The objective of this study was to examine whether LQTS mutation carrier status or symptomatic LQTS are associated with an increased risk of depression or any of its dimensions (affective, cognitive, and somatic), and whether there are sex differences in these potential relationships.

\section{Methods}

\section{Participants and Procedures}

Participants were recruited from the Finnish LQTS registry consisting of individuals from whole Finland who have been referred for genetic testing for LQTS since 1993. Direct DNA sequencing and restriction enzyme assays were used to identify LQTS mutations as previously described (Fodstad et al. 2004, 2006). Registry members fulfilling the following criteria were included in psychological evaluation: a molecularly verified or excluded familial LQTS mutation, age greater than or equal to 18, permanent residency in Finland, and a written informed consent. The classification of the mutations was performed according to Richards et al. (2015) using information obtained from the following databases:

$\mathrm{SISu}$ (http://www.sisuproject.fi/),

Exome Variant Server (http://evs.gs.washington. edu/EVS/),

ExAC (http://exac.broadinstitute.org/), dbSNP (http://www.ncbi.nlm.nih.gov/snp/), 
HGMD (http://www.hgmd.cf.ac.uk/ac/index.php), ClinVar (http://www.ncbi.nlm.nih.gov/clinvar/),

ExAC: http://biorxiv.org/content/early/2015/10/30 $/ 030338$, and

HGMD (Stenson et al. 2003).

Pathogenic and likely pathogenic mutations, and variants of unknown significance were included in the study, while benign and likely benign variants were excluded. SCN5A R104Q and SCN5A E1784K mutations were excluded due to being associated with both LQTS and Brugada syndrome (Moric et al. 2003). The genetic test results were reviewed in 2016. The study was approved by the Helsinki University Central Hospital (April 6, 2011).

In 2011, psychological study questionnaires were sent to 1443 individuals who had participated in the previous data collection phase in 2006. There were 1081 (74.9\%) people who responded. Of them, $254(23.5 \%)$ individuals had some missing information on the study variables and $45(4.2 \%)$ individuals were excluded due to redefinition of age criteria (age $\leq 75$ ). Thus, the final sample comprised 782 participants (252 men). There were 369 LQTS mutation carriers (113 men). The control group consisted of 413 relatives (139 men) not carrying a familial LQTS-causing mutation. There were $263 \mathrm{KCNQ1}, 87 \mathrm{KCNH} 2,12 \mathrm{SCN} 5 \mathrm{~A}$, and six KCNJ2 (Andersen-Tawil syndrome) mutation carriers. One participant was a carrier of both $K C N Q 1$ and $K C N H 2$ mutations.

\section{Instrumentation}

Information regarding the history of arrhythmic events was collected with a questionnaire when a person was entered into the LQTS registry. The data were updated in 2011 when the present study was carried out. Those LQTS mutation carriers who had experienced a documented LQTS-type syncopal episode and/or aborted cardiac arrest were grouped as symptomatic and those without the symptoms as asymptomatic LQTS mutation carriers.

Depression was assessed using the 21-item Beck Depression Inventory-II (BDI-II) (Beck et al. 1996) designed to screen for depressive disorder based on criteria from the Diagnostic and Statistical Manual of Mental Disorders, Fourth Edition (DSM-IV). The participants were asked to describe how they have been feeling during the past 2 weeks. Each item had four alternative statements (except for items concerning change in sleeping and eating habits with seven statements in order to better evaluate the decrease or increase in these items). The total possible score for depression ranged from 0 to 63 (0-3 points for each item). Reliability of the scale was high (Cronbach's $\alpha=.92$ ). We calculated the sum score of responses and additionally categorized the participants into two groups according to whether they screened positively or negatively for depressive disorder in order to find out the prevalence of depressive disorder (from mild to severe) in the sample. The cut-off score of 14 points was used as briefed in the manual (Beck et al. 1996). The three dimensions of depression were based on the three-factor model of the BDI-II (Beck et al. 2002). The affective dimension consisted of five items $(1,2,4,9$, and 12), the cognitive dimension was defined by seven items $(3,5-8,13$, and 14$)$, and the somatic dimension consisted of nine items (10, 11, and 15-21). Each of the subscales showed high reliability (affective dimension Cronbach's $\alpha=.80$, cognitive dimension Cronbach's $\alpha=.87$, and somatic dimension Cronbach's $\alpha=.82$ ).

Perceived social support was self-rated with the Multidimensional Scale of Perceived Social Support (MSPSS) (Zimet et al. 1988) that consists of 12 items such as: There is a special person who is around when I am in need, I get the emotional help and support I need from my family, I can count on my friends when things go wrong. The participants were asked to rate how well each statement describes them. A 5point response scale (ranging from $1=$ strongly disagree to 5 = strongly agree) was used instead of the original 7-point scale. The questionnaire reliability was .96 (Cronbach's $\alpha$ ). The mean value of responses was calculated.

The participants reported their education as completed degrees. We classified them into two groups: lower (basic/vocational education including degrees from a university of applied sciences) and higher (university degree) education levels.

\section{Data Analysis}

First, the association between LQTS mutation carrier status and depression (linear variable) was tested by conducting binary logistic regression (comparing LQTS mutation carriers with the control group). Then, the association between symptomatic LQTS and depression (linear variable) was examined by multinomial (comparing symptomatic and asymptomatic LQTS mutation carriers with the control group) and binary (comparing symptomatic LQTS mutation carriers with asymptomatic LQTS mutation carriers) logistic regression analyses. The associations were tested controlling for age, $\beta$-blockers, antidepressants, social support, and education. The analyses were performed separately for women and men as a marginally significant interaction effect of LQTS mutation carrier status and sex on depression was found $(p=.059)$ in the analysis of variance (two-way ANOVA). The differences between women and men in the study variables were tested with a chi-square test, a $t$-test, and a one-way ANOVA. The attrition analysis was carried out with a $t$-test. All the statistical analyses were conducted using PASW 18.0.2. software.

\section{Results}

The individuals included in the present study $(n=782)$ were younger compared with the 254 persons lost due to attrition 
(49.40 vs. $54.86, p<.001)$. The groups did not differ in social support or depression $(p s>.05)$.

The characteristics of the final sample by sex are summarized in Table 1. Of the 256 LQTS mutation carrier women, $131(51.2 \%)$ had experienced an arrhythmic event at least once in a lifetime. Of the 113 LQTS mutation carrier men, $38(33.6 \%)$ had had arrhythmic events. More women than men had experienced arrhythmic events $(p=.002)$. Men were older than women (51.08 vs. 48.61, $p=.024)$. Women scored higher on depression (7.01 vs. $4.73, p<.001)$ compared with men. More women than men screened positively for depressive disorder $(15.8 \%$ vs. $9.1 \%, p=.011)$.

We additionally compared women and men according to LQTS symptom status group. In the symptomatic LQTS group, women and men differed in $\beta$-blocker treatment $(71.8 \%$ vs. $39.5 \%, p<.001)$. In the asymptomatic LQTS group, women scored higher than men on depression (6.67 vs. 3.92, $p=.008$ ) and its cognitive ( 1.74 vs. $0.96, p=.042)$ and somatic dimension (3.86 vs. $2.28, p=.002$ ). In the control group, women scored higher on depression $(7.18$ vs. $4.37, p<.001)$ and its affective (1.31 vs. $0.88, p=.019)$, cognitive (1.78 vs. $1.14, p=.020)$, and somatic dimension (4.08 vs. $2.35, p<.001)$ compared with men. Women from the control group also reported higher social support (3.97 vs. 3.68, $p=.002)$ and education level $(29.1 \%$ vs. $18.5 \%, p=.040)$, and were more often users of antidepressants $(8.4 \%$ vs. $2.2 \%, p=.014)$ than men.

No association was found for LQTS mutation carrier status with depression (tested using binary logistic regression) when comparing LQTS mutation carriers with the control group and adjusting for age, $\beta$-blockers, antidepressants, and social support (women: $O R=1.00,95 \% C I[0.97,1.03], p=.93$, $R^{2}=23.3 \%$; men: $O R=1.03,95 \% C I[0.98,1.08]$, $p=.25, R^{2}=11.1 \%$ ). Similarly, there were no associations between LQTS mutation carrier status and any of the dimensions of depression in either women or men $(p s>.05)$. We additionally adjusted the associations for education (the analysis had to be carried out on a smaller sample because of missing information on education for 186 participants [398 women and 198 men]), but this had no effect on any of the associations $(p s>.05)$.

Table 2 presents the results of the multinomial logistic regression in which LQTS mutation carriers with arrhythmic events and LQTS mutation carriers without arrhythmic events were compared with the control group. Symptomatic LQTS was associated with depression in men independently of age, $\beta$-blocker treatment, antidepressant use, and social support
Table 1 The characteristics of the study sample by sex

\begin{tabular}{|c|c|c|c|c|c|c|c|}
\hline \multirow[t]{2}{*}{ Study variables } & \multicolumn{3}{|c|}{ Women $(n=530)$} & \multicolumn{4}{|l|}{$\operatorname{Men}(n=252)$} \\
\hline & Mean/number & $S D / \%$ & Range & Mean/ number & $S D / \%$ & Range & $p$-value \\
\hline Age (years) & 48.61 & 14.86 & $19-75$ & 51.08 & 13.99 & $19-75$ & .024 \\
\hline \multicolumn{8}{|l|}{ Medication } \\
\hline$\beta$-blockers & 174 & 32.8 & & 47 & 18.7 & & $<.001$ \\
\hline Antidepressants & 45 & 8.5 & & 12 & 4.8 & & .061 \\
\hline Social support & 4.09 & 0.88 & $1-5$ & 3.81 & 0.98 & $1-5$ & $<.001$ \\
\hline Depressive disorder & & & & & & & .011 \\
\hline Yes & 84 & 15.8 & & 23 & 9.1 & & \\
\hline No & 446 & 84.2 & & 229 & 90.9 & & \\
\hline Depression (linear) & 7.01 & 7.37 & $0-38$ & 4.73 & 6.42 & $0-55$ & $<.001$ \\
\hline Affective dimension & 1.21 & 1.84 & $0-12$ & 0.90 & 1.68 & $0-12$ & .020 \\
\hline Cognitive dimension & 1.84 & 2.75 & $0-15$ & 1.24 & 2.31 & $0-21$ & .002 \\
\hline Somatic dimension & 3.95 & 3.60 & $0-17$ & 2.58 & 3.10 & $0-22$ & $<.001$ \\
\hline \multicolumn{8}{|l|}{ Group status } \\
\hline \multicolumn{8}{|l|}{ LQTS mutation carrier } \\
\hline Status & 256 & 48.3 & & 113 & 44.9 & & \\
\hline Symptomatic LQTS & 131 & 24.7 & & 38 & 15.1 & & \\
\hline Asymptomatic LQTS & 125 & 23.6 & & 75 & 29.8 & & $.002^{\mathrm{a}}$ \\
\hline Control group & 274 & 51.7 & & 139 & 55.2 & & \\
\hline Education $^{\mathrm{b}}$ & & & & & & & .15 \\
\hline Lower & 281 & 70.6 & & 151 & 76.3 & & \\
\hline Higher & 117 & 29.4 & & 47 & 23.7 & & \\
\hline
\end{tabular}

Abbreviations: LQTS, long QT syndrome; $n$, number of participants; $S D$, standard deviation

${ }^{\text {a }}$ Chi-square test comparing proportions of women and men in symptomatic and asymptomatic LQTS status group

${ }^{\mathrm{b}}$ Women $n=398$, men $n=198$ 
Table 2 The results of multinomial logistic regression examining the association between lqts symptom status and depression

\begin{tabular}{|c|c|c|c|c|c|c|c|c|}
\hline \multirow[t]{2}{*}{ Group status } & \multicolumn{4}{|c|}{$\operatorname{Women}(n=530)$} & \multicolumn{4}{|c|}{$\operatorname{Men}(n=252)$} \\
\hline & $n$ & OR $(95 \% C I)$ & $p$-value & $R^{2}(\%)$ & $n$ & OR $(95 \% C I)$ & $p$-value & $R^{2}(\%)$ \\
\hline Model 1 & & & & 0.1 & & & & 3.5 \\
\hline Control group & 274 & 1.00 & & & 139 & 1.00 & & \\
\hline Asymptomatic LQTS & 125 & $0.99(0.96,1.02)$ & .53 & & 75 & $0.98(0.93,1.04)$ & .56 & \\
\hline Symptomatic LQTS & 131 & $1.00(0.97,1.03)$ & .80 & & 38 & $\mathbf{1 . 0 6}(1.01,1.11)$ & .020 & \\
\hline Model 2 & & & & 27.3 & & & & 15.1 \\
\hline Control group & 274 & 1.00 & & & 139 & 1.00 & & \\
\hline Asymptomatic LQTS & 125 & $1.01(0.97,1.04)$ & .79 & & 75 & $0.99(0.93,1.05)$ & .67 & \\
\hline Symptomatic LQTS & 131 & $1.00(0.96,1.04)$ & .85 & & 38 & $\mathbf{1 . 0 9}(1.02,1.15)$ & .007 & \\
\hline
\end{tabular}

Abbreviations: $C I$, confidence interval; $n$, number of participants; $O R$, odds ratio; $R^{2}$ (Nagelkerke), fraction of explained variance

Reference group $=$ control group

Model 1 unadjusted

Model 2 adjusted for age, $\beta$-blockers, antidepressants, and social support

Values of the coefficients in bold indicate statistical significance

$\left(O R=1.09,95 \% C I[1.02,1.15], p=.007, R^{2}=15.1 \%\right)$. Controlling additionally for education did not change the results $\left(O R=1.09,95 \% C I[1.02,1.16], p=.008, R^{2}=20.1 \%\right)$. No associations were found in women ( $p \mathrm{~s}>.05)$.

We also conducted a multinomial logistic regression analysis for the three dimensions of depression. There were associations of symptomatic LQTS with the cognitive $(O R=1.22$, $\left.95 \% C I[1.04,1.42], p=.013, R^{2}=14.4 \%\right)$ and the somatic dimension $(O R=1.19,95 \% C I[1.05,1.34], p=.005$, $R^{2}=14.8 \%$ ) in men when controlling for age, $\beta$-blockers, antidepressants, and social support, while the association with the affective dimension was marginally significant $\left(O R=1.23,95 \% C I[1.00,1.52], p=.054, R^{2}=13.5 \%\right)$. After adjustment additionally for education, the associations of symptomatic LQTS with the cognitive $(O R=1.24,95 \% C I$ $\left.[1.05,1.47], p=.011, R^{2}=19.6 \%\right)$ and the somatic dimension $\left(O R=1.20,95 \% C I[1.05,1.37], p=.006, R^{2}=20.3 \%\right)$ remained significant, whereas the association with the affective dimension continued to be marginally significant $\left(O R=1.24,95 \% C I[0.99,1.54], p=.061, R^{2}=16.9 \%\right)$.

In the binary logistic regression comparing LQTS mutation carriers with and without arrhythmic events, symptomatic LQTS was associated with depression in men after adjusting for age, $\beta$-blockers, antidepressive medication, and social support $(O R=1.10,95 \% C I[1.03,1.19], p=.009$, $R^{2}=16.0 \%$ ) (Table 3 ). The results remained significant when we repeated the analysis controlling additionally for education $\left(O R=1.14,95 \% C I[1.03,1.25], p=.011, R^{2}=23.7 \%\right)$. The association between symptomatic LQTS and depression was not found in women $(p \mathrm{~s}>.05)$.

The binary logistic regression analysis performed with the three dimensions of depression showed that symptomatic LQTS was associated with the affective $(O R=1.41,95 \%$ $C I$ [1.07, 1.87], $p=.017, R^{2}=13.7 \%$ ), the cognitive
$\left(O R=1.28,95 \% C I[1.04,1.56], p=.020, R^{2}=14.1 \%\right)$, and the somatic dimension $(O R=1.19,95 \% C I[1.04,1.36]$, $\left.p=.009, R^{2}=14.5 \%\right)$ in men independently of age, $\beta$ blockers, antidepressants, and social support. When controlling additionally for education, the associations of symptomatic LQTS with the cognitive $(O R=1.37,95 \% C I[1.03$, $\left.1.83], p=.032, R^{2}=21.3 \%\right)$ and the somatic dimension $\left(O R=1.29,95 \% C I[1.08,1.54], p=.005, R^{2}=24.6 \%\right)$ remained significant, but the association with the affective dimension was attenuated to marginally significant $\left(O R=1.31,95 \% C I[0.97,1.76], p=.080, R^{2}=16.4 \%\right)$.

\section{Discussion}

We examined whether LQTS mutation carrier status or symptomatic LQTS are associated with an increased risk of depression or its three dimensions (affective, cognitive, and somatic), and whether there are sex differences in these relationships. The results showed no associations between being a LQTS mutation carrier and depression or any of its three dimensions. Symptomatic LQTS was associated with depression in men independently of age, $\beta$-blocker and antidepressant treatment, social support, and education. Women scored higher on depression and all its dimensions compared with men. Also, more women than men screened positively for depressive disorder and had experienced cardiac events. Nevertheless, there were no associations of symptomatic LQTS with either depression or any of the three dimensions of depression in women.

Carrying a LQTS-causing mutation and thus being at risk of potentially fatal arrhythmias was not associated with depression. This is in line with our previous study (Hintsa et al. 2009) in which no association is evident between being 
Table 3 The results of binary logistic regression examining the association between lqts symptom status and depression

\begin{tabular}{|c|c|c|c|c|c|c|c|c|}
\hline \multirow[t]{2}{*}{ Group status } & \multicolumn{4}{|c|}{$\operatorname{Women}(n=256)$} & \multicolumn{4}{|c|}{$\operatorname{Men}(n=113)$} \\
\hline & $n$ & OR $(95 \% C I)$ & $p$-value & $R^{2}(\%)$ & $n$ & OR $(95 \% C I)$ & $p$-value & $R^{2}(\%)$ \\
\hline Model 1 & & & & 0.1 & & & & 7.8 \\
\hline Asymptomatic LQTS & 125 & 1.00 & & & 75 & 1.00 & & \\
\hline Symptomatic LQTS & 131 & $1.01(0.97,1.04)$ & .74 & & 38 & $\mathbf{1 . 0 8}(1.01,1.16)$ & .024 & \\
\hline Model 2 & & & & 20.6 & & & & 16.0 \\
\hline Asymptomatic LQTS & 125 & 1.00 & & & 75 & 1.00 & & \\
\hline Symptomatic LQTS & 131 & $0.99(0.95,1.03)$ & .63 & & 38 & $\mathbf{1 . 1 0}(1.03,1.19)$ & .009 & \\
\hline
\end{tabular}

Abbreviations: $C I$, confidence interval; $n$, number of participants; $O R$, odds ratio, $R^{2}$ (Nagelkerke), fraction of explained variance

Reference group = asymptomatic LQTS

Model 1 unadjusted

Model 2 adjusted for age, $\beta$-blockers, antidepressants, and social support

Values of the coefficients in bold indicate statistical significance

aware of LQTS mutation carrier status and an increased vulnerability to depressive symptoms. It has been suggested (Hendriks et al. 2008) that it is not knowledge of the disorder, but rather uncertainty related to the LQTS diagnosis that leads to a tendency for depressive mood, at least in the short term.

Our study showed that symptomatic LQTS may increase the risk of depression in men. We also found that symptomatic LQTS was associated with the dimensions of depression, i.e., its affective, cognitive, and somatic dimension. LQTS mutation carriers with a history of cardiac symptoms (especially those with LQT1 - a subtype of LQTS being the most prevalent within symptomatic LQTS men in our study sample and largely associated with exercise-induced symptoms) are advised to avoid strenuous physical activity (Priori et al. 2013). Consequently, they could be physically less fit and thus experience greater fatigue than others. The association between symptomatic LQTS and depression could result mainly from tiredness related to a poor physical condition or symptoms themselves, but the present study showed that this is not the case. Symptomatic LQTS was more strongly associated with the psychological symptoms of depression, i.e., its affective and cognitive dimension, than with the somatic symptoms of depression.

The current results are in line with our previous findings showing that symptomatic LQTS is associated with prolonged mental stress (Hintsa et al. 2010) and a tendency to depressive mood (Hintsa et al. 2009). The frequency of stressful life events (i.e., death or illness of a family member, financial difficulties, significant interpersonal conflicts, and mental and physical assaults) has been reported to be higher in symptomatic LQTS mutation carriers (Hintsa et al. 2010). Stressful life events, in turn, have been shown to be associated with increased emotional distress (Määttänen et al. 2013a) and depressive symptoms in symptomatic LQTS mutation carriers (Hintsa et al. 2016). Sex differences have not been detected in these previous studies (Hintsa et al. 2009, 2010, 2016; Määttänen et al. 2013a).

\section{Potential Mechanisms}

Sex differences in the self-concept (Cross and Madson 1997) and stress responses (Stroud et al. 2002) may be mechanisms underlying sex differences in depression. Men may tend to construct and maintain their self-definition based on their unique skills and pursuit of independence (independent selfconstrual), whereas self-definition in women has been suggested to be largely based on their social relationships and pursuit of harmony (interdependent self-construal) (Cross and Madson 1997). It has also been reported (Stroud et al. 2002) that men have greater physiological reactivity to achievement stressors, while women are more reactive to social stressors. In view of this, symptomatic LQTS may have a greater impact on mental health of men than women since the disorder may limit major life activities and independence, and inhibit habitual achievement strivings through periodic feelings of exhaustion or the need to avoid activities that can trigger arrhythmic events (Andersen et al. 2008). In particular, cardiac symptoms can negatively affect working life of LQTS patients, for example, due to the need to take a day off work or being late (Andersen et al. 2008). This, in turn, together with an increased cost of health care, may result in higher work stress which has been shown to be more strongly associated with depression in men than women (Shields 2006).

In addition to the fact that symptomatic LQTS may lead to depression in men, depression may increase the risk of arrhythmic events. It has been shown (Carney et al. 1993; Watkins et al. 2006) that depression can enhance the likelihood of ventricular arrhythmias in patients with coronary artery disease. Furthermore, depression has been linked to prolonged mental stress (Hammen et al. 2009) that may compromise the physiological capacity to cope with stress (Keltikangas-Jarvinen et al. 1996). This may be attributable to the autonomic nervous system function since previous research (Carney et al. 2002) has shown that depression is 
associated with an increased sympathetic and/or decreased parasympathetic activity. This imbalance, in turn, has been suggested to play an important role in the dynamic change in the QT-interval and the initiation of torsade de pointes (i.e., a specific form of ventricular tachycardia) in LQTS mutation carriers (Fujiki et al. 2001). Human and non-human animal research (Dart et al. 2002) has reported sex differences in the function of the autonomic nervous system: males showing a higher cardiac sympathetic responsiveness and females showing a higher cardiac parasympathetic responsiveness. Therefore, LQTS mutation carrier men may be at a higher risk of arrhythmic events due to depression.

Physical inactivity may be another factor that could explain the presence of the association between symptomatic LQTS and depression in men and not in women in both directions. LQTS mutation carriers with arrhythmic events have restrictions on their physical exercise (Priori et al. 2013), which has been shown to protect against common mood and anxiety states among men (Bhui and Fletcher 2000) and to prevent inflammatory processes (Hamer et al. 2012). The latter, in turn, has been suggested to induce depressive symptoms in men but not in women (Elovainio et al. 2009). Conversely, depression may result in exercise withdrawal (RoshanaeiMoghaddam et al. 2009). Depressive symptoms, being partly responsible for proinflammatory processes in men (Elovainio et al. 2009), together with physical inactivity seem to interact to increase cardiovascular mortality risk (Kamphuis et al. 2007). Depression has also been associated with a heightened expression of inflammation and coagulation markers implicated in the pathogenesis of cardiac disease (Panagiotakos et al. 2004).

\section{Study Limitations and Research Recommendations}

Some limitations of the study should be considered when interpreting the results. First, as the study was cross-sectional, it does not allow conclusions about the causality. Thus, it is equally likely that symptomatic LQTS may lead to depression in men or that depression may increase the risk of arrhythmic events in LQTS mutation carrier men. A bidirectional association that could proceed to a vicious cycle is also possible. Second, depression was self-reported and defining depressive disorder did not include a clinical diagnosis of depression. As the analyzed data was based on self-report measures, some reporting bias could arise. Self-reported depression is, however, unlikely to be severely affected by reporting bias because we used BDI-II (Beck et al. 1996), a valid instrument to screen for depressive disorder based on criteria from the DSM-IV. Third, potential non-response to the BDI-II may also bias the results. It is possible that those who did not respond were either not able to do this due to feeling depressed or not interested in participating because they did not experience depression. Fourth, the self-reported arrhythmic events in LQTS mutation carriers may include some that are not LQTS-type ventricular arrhythmias, and the proportion of such is unknown. Finally, the control group consisted of unaffected relatives of LQTS mutation carriers who might not have been validly comparable to the cases. There is the possibility that they could feel worried about their family members having a LQTS-causing mutation, experience guilt towards them because of not carrying the familial LQTS mutation ("survivor guilt"), and/or be stressed about caregiver responsibilities.

Our findings indicate that prospective studies are needed to determine the direction of the association between symptomatic LQTS and depression. Mechanisms underlying this association are unclear, and thus warrant further research. Furthermore, we suggest that future studies could benefit from including clinically diagnosed depression and a populationbased control group. Also, examining whether an increase in the severity of cardiac symptoms in LQTS mutation carriers is associated with a higher risk of depression could be valuable.

\section{Study Strengths and Practice Implications}

The study has several strengths. We used a sample of molecularly genotyped LQTS mutation carriers. Furthermore, we used a valid measure of depression which is meant to screen for depressive disorder. We were also able to consider dimensions of depression and several potential confounders, such as targeted medications for LQTS and depression, social support, and education, all of which are important when studying depression.

Our results indicate that it may be important to focus on preventive care and treatment of depression as an integral component of practice in the health care of all LQTS mutation carriers and their unaffected relatives. We recommend that primary health-care professionals, cardiologists, and genetic counselors should be trained in routine checking for depression in people carrying a LQTS-causing mutation and in the management of those who screened positively for depression (e.g., referring the patients to mental health specialists). Therefore, informing this group of patients of the importance of attending regular physical and mental health checks, and encouraging them to report any negative mood changes can be important.

Genetic counseling has been described as a time-limited, highly circumscribed form of psychotherapy in which effective communication of genetic information is the main therapeutic goal (Austin et al. 2014). Individuals with hypertrophic cardiomyopathy (i.e., a heritable condition associated with an increased risk of sudden cardiac death) who attend specialized cardiac genetic clinics, providing genetic counseling, have shown to be better adjusted, less worried, and less depressed compared with those who do not (Ingles et al. 2008). Also, LQTS mutation patients have described their contact with a genetic counselor as a positive experience (Andersen et al. 2008). Given this, we suggest that offering genetic counseling can be beneficial for prevention and treatment of depression in 
LQTS mutation carriers and their family members. The inclusion of career counseling in people affected with LQTScausing mutation could also be of value.

\section{Conclusions}

We found that being diagnosed as a LQTS mutation carrier is not associated with depression. In men, symptomatic LQTS is associated with an increased risk of depression and its affective, cognitive, and somatic dimension independently of age, selected medication ( $\beta$-blockers and antidepressants), social support, and education. More women than men experience arrhythmic events. Also, women score higher on depression and all its dimensions compared with men, and a greater number of women than men screen positively for depressive disorder. The general tendency of women to report more depressive symptoms compared with men might account for their higher levels of depression and greater likelihood of meeting criteria for depressive disorder (Piccinelli and Wilkinson 2000). However, symptomatic LQTS is not associated with depression in women. Together, these findings suggest that regular screening for depression in all LQTS mutation carriers and their unaffected family members can be important.

Acknowledgments This study was supported by the Academy of Finland Grant 258711 awarded to Liisa Keltikangas-Järvinen, and the Finnish Funding Agency for Innovation Grant 2510/31/2013 awarded to Ilmari Määttänen. We thank Mauri Niiniaho and Paavo Nelke for their help in the data collection and related procedures.

\section{Compliance with Ethical Standards}

Conflict of Interest Karolina Wesołowska, Marko Elovainio, Mikael Koponen, Annukka M. Tuiskula, Mirka Hintsanen, Liisa KeltikangasJärvinen, Ilmari Määttänen, Heikki Swan, and Taina Hintsa declare that they have no conflict of interest.

Human Studies and Informed Consent All procedures followed were in accordance with the ethical standards of the responsible committee on human experimentation (institutional and national) and with the Helsinki Declaration of 1975, as revised in 2000 (5). Informed consent was obtained from all patients for being included in the study.

Animal Studies No animal studies were carried out by the authors for this article.

\section{References}

Andersen, J., Øyen, N., Bjorvatn, C., \& Gjengedal, E. (2008). Living with long QT syndrome: A qualitative study of coping with increased risk of sudden cardiac death. Journal of Genetic Counseling, 17(5), 489-498.

Austin, J., Semaka, A., \& Hadjipavlou, G. (2014). Conceptualizing genetic counseling as psychotherapy in the era of genomic medicine. Journal of Genetic Counseling, 23(6), 903-909.
Beck, A., Steer, R., \& Brown, G. (1996). BDI-II, Beck Depression Inventory: Manual (2nd ed.). Boston: Harcourt Brace.

Beck, A., Steer, R., Brown, G., \& Van der Does, A. (2002). BDI-II-Dutch manual. Lisse, Netherlands: Psychological Corporation.

Berlin, A. A., Kop, W. J., \& Deuster, P. A. (2006). Depressive mood symptoms and fatigue after exercise withdrawal: The potential role of decreased fitness. Psychosomatic Medicine, 68(2), 224-230.

Bhui, K., \& Fletcher, A. (2000). Common mood and anxiety states: Gender differences in the protective effect of physical activity. Social Psychiatry and Psychiatric Epidemiology, 35(1), 28-35.

Brink, P. A., Crotti, L., Corfield, V., Goosen, A., Durrheim, G., Hedley, P., ...Schwartz, P. J. (2005). Phenotypic variability and unusual clinical severity of congenital long-QT syndrome in a founder population. Circulation, 112(17), 2602-2610.

Burgess, C., Cornelius, V., Love, S., Graham, J., Richards, M., \& Ramirez, A. (2005). Depression and anxiety in women with early breast cancer: Five year observational cohort study. BMJ. doi:10.1136/bmj.38343.670868.D3

Carney, R., Freedland, K., Rich, M., Smith, L., \& Jaffe, A. (1993). Ventricular tachycardia and psychiatric depression in patients with coronary artery disease. American Journal of Medicine, 95(1), 2328.

Carney, R. M., Freedland, K. E., Miller, G. E., \& Jaffe, A. S. (2002). Depression as a risk factor for cardiac mortality and morbidity: A review of potential mechanisms. Journal of Psychosomatic Research, 53(4), 897-902.

Ciesla, J. A., \& Roberts, J. E. (2001). Meta-analysis of the relationship between HIV infection and risk for depressive disorders. American Journal of Psychiatry, 158(5), 725-730.

Cross, S., \& Madson, L. (1997). Models of the self: Self-construals and gender. Psychological Bulletin, 122(1), 5-37.

Dart, A. M., Du, X.-J., \& Kingwell, B. A. (2002). Gender, sex hormones and autonomic nervous control of the cardiovascular system. Cardiovascular Research, 53(3), 678-687.

Dickens, C., McGowan, L., Clark-Carter, D., \& Creed, F. (2002). Depression in rheumatoid arthritis: A systematic review of the literature with meta-analysis. Psychosomatic Medicine, 64(1), 52-60.

Dickens, C. M., Percival, C., McGowan, L., Douglas, J., Tomenson, B., Cotter, L., et al. (2004). The risk factors for depression in first myocardial infarction patients. Psychological Medicine, 34(6), 10831092

Elovainio, M., Aalto, A.-M., Kivimäki, M., Pirkola, S., Sundvall, J., Lönnqvist, J., \& Reunanen, A. (2009). Depression and C-reactive protein: Population-based Health 2000 Study. Psychosomatic Medicine, 71(4), 423-430.

Farnsworth, M. M., Fosyth, D., Haglund, C., \& Ackerman, M. J. (2006). When I go in to wake them . I wonder: Parental perceptions about congenital long QT syndrome. Journal of the American Academy of Nurse Practitioners, 18(6), 284-290.

Fodstad, H., Swan, H., Laitinen, P., Piippo, K., Paavonen, K., Viitasalo, M., et al. (2004). Four potassium channel mutations account for $73 \%$ of the genetic spectrum underlying long-QT syndrome (LQTS) and provide evidence for a strong founder effect in Finland. Annals of Medicine, 36(Suppl 1), 53-63.

Fodstad, H., Bendahhou, S., Rougier, J.-S., Laitinen-Forsblom, P. J., Barhanin, J., Abriel, H., et al. (2006). Molecular characterization of two founder mutations causing long QT syndrome and identification of compound heterozygous patients. Annals of Medicine, 38(4), 294-304.

Fujiki, A., Nishida, K., Mizumaki, K., Nagasawa, H., Shimono, M., \& Inoue, H. (2001). Spontaneous onset of torsade de pointes in longQT syndrome and the role of sympathovagal imbalance. Japanese Circulation Journal, 65(12), 1087-1090. 
Giudicessi, J. R., \& Ackerman, M. J. (2013a). Determinants of incomplete penetrance and variable expressivity in heritable cardiac arrhythmia syndromes. Translational Research, 161(1), 1-14.

Giudicessi, J. R., \& Ackerman, M. J. (2013b). Genotype- and phenotypeguided management of congenital long QT syndrome. Current Problems in Cardiology, 38(10), 417-455.

Hamer, M., Sabia, S., Batty, G. D., Shipley, M. J., Tabak, A. G., Singh-Manoux, A., \& Kivimaki, M. (2012). Physical activity and inflammatory markers over 10 years: Follow-up in men and women fom the Whitehall II Cohort Study. Circulation, 126(8), 928-933.

Hammen, C., Kim, E. Y., Eberhart, N. K., \& Brennan, P. A. (2009). Chronic and acute stress and the prediction of major depression in women. Depression and Anxiety, 26(8), 718-723.

Hendriks, K. S. W. H., Hendriks, M. M. W. B., Birnie, E., Grosfeld, F. J. M., Wilde, A. A. M., van den Bout, J., et al. (2008). Familial disease with a risk of sudden death: A longitudinal study of the psychological consequences of predictive testing for long QT syndrome. Heart Rhythm, 5(5), 719-724.

Hintsa, T., Keltikangas-Järvinen, L., Puttonen, S., Ravaja, N., Toivonen, L., Kontula, K., \& Swan, H. (2009). Depressive symptoms in the congenital long QT syndrome. Annals of Medicine, 41(7), 516-521.

Hintsa, T., Puttonen, S., Toivonen, L., Kontula, K., Swan, H., \& Keltikangas-Järvinen, L. (2010). A history of stressful life events, prolonged mental stress and arrhythmic events in inherited long QT syndrome. Heart (British Cardiac Society), 96(16), 1281-1286.

Hintsa, T., Jokela, M., Elovainio, M., Määttänen, I., Swan, H., Hintsanen, M., et al. (2016). Stressful life events and depressive symptoms among symptomatic long QT syndrome patients. Journal of Health Psychology, 21(4), 505-512.

Huffman, J. C., Celano, C. M., Beach, S. R., Motiwala, S. R., \& Januzzi, J. L. (2013). Depression and cardiac disease: Epidemiology, mechanisms, and diagnosis. Cardiovascular Psychiatry and Neurology. doi:10.1155/2013/695925

Ingles, J., Lind, J. M., Phongsavan, P., \& Semsarian, C. (2008). Psychosocial impact of specialized cardiac genetic clinics for hypertrophic cardiomyopathy. Genetics in Medicine, 10(2), 117-120.

Kamphuis, M. H., Geerlings, M. I., Tijhuis, M. A. R., Giampaoli, S., Nissinen, A., Grobbee, D. E., \& Kromhout, D. (2007). Physical inactivity, depression, and risk of cardiovascular mortality. Medicine and Science in Sports and Exercise, 39(10), 16931699.

Keltikangas-Jarvinen, L., Ravaja, N., Raikkonen, K., \& Lyytinen, H. (1996). Insulin resistance syndrome and autonomically mediated physiological responses to experimentally induced mental stress in adolescent boys. Metabolism, 45(5), 614-621.

Locati, E. H., Zareba, W., Moss, A. J., Schwartz, P. J., Vincent, G. M., Lehmann, M. H., et al. (1998). Age- and sex-related differences in clinical manifestations in patients with congenital long-QT syndrome: Findings from the International LQTS Registry. Circulation, 97(22), 2237-2244.

Määttänen, I., Hintsa, T., Toivonen, L., Swan, H., Pulkki-Råback, L., Hintsanen, M., et al. (2011). Cloninger's temperament traits and inherited long QT syndrome. Journal of Psychosomatic Research, 71(4), 245-249.

Määttänen, I., Jokela, M., Pulkki-Raback, L., Keltikangas-Jarvinen, L., Swan, H., Toivonen, L., et al. (2013a). Brief report: Emotional distress and recent stressful life events in long QT syndrome mutation carriers. Journal of Health Psychology, 20(11), 1445-1450.

Määttänen, I., Keltikangas-Järvinen, L., Swan, H., Toivonen, L., Kontula, K., Hintsanen, M., ...Hintsa, T. (2013b). Stress proneness in molecularly defined long QT syndrome: A study using temperament assessment by Behavioural Inhibition System scale. Stress and Health, 29(2), 150-155.
Marjamaa, A., Salomaa, V., Newton-Cheh, C., Porthan, K., Reunanen, A., Karanko, H., et al. (2009). High prevalence of four long QT syndrome founder mutations in the Finnish population. Annals of Medicine, 41(3), 234-240.

Moller-Leimkuhler, A. (2007). Gender differences in cardiovascular disease and comorbid depression. Dialogues in Clinical Neuroscience, 9(1), 71-83.

Moric, E., Herbert, E., Trusz-Gluza, M., Filipecki, A., Mazurek, U., \& Wilczok, T. (2003). The implications of genetic mutations in the sodium channel gene (SCN5A). Europace, 5(4), 325-334.

Panagiotakos, D. B., Pitsavos, C., Chrysohoou, C., Tsetsekou, E., Papageorgiou, C., Christodoulou, G., et al. (2004). Inflammation, coagulation, and depressive symptomatology in cardiovascular disease-free people; the ATTICA study. European Heart Journal, 25(6), 492-499.

Paykel, E. (1994). Life events, social support and depression. Acta Psychiatrica Scandinavica Suppl, 377, 50-58.

Piccinelli, M., \& Wilkinson, G. (2000). Gender differences in depression. Critical review. The British Journal of Psychiatry, 177(6), 486-492.

Priori, S. G., Napolitano, C., \& Schwartz, P. J. (1999). Low penetrance in the long-QT syndrome: Clinical impact. Circulation, 99(4), 529-533

Priori, S. G., Wilde, A. A., Horie, M., Cho, Y., Behr, E. R., Berul, C., et al. (2013). HRS/EHRA/APHRS Expert Consensus Statement on the Diagnosis and Management of Patients with Inherited Primary Arrhythmia Syndromes: Document endorsed by HRS, EHRA, and APHRS in May 2013 and by ACCF, AHA, PACES, and AEPC in June 2013. Heart Rhythm, 10(12), 1932-1963.

Richards, S., Aziz, N., Bale, S., Bick, D., Das, S., Gastier-Foster, J., et al. (2015). Standards and guidelines for the interpretation of sequence variants: A joint consensus recommendation of the American College of Medical Genetics and Genomics and the Association for Molecular Pathology. Genetics in Medicine, 17(5), 405-424.

Roshanaei-Moghaddam, B., Katon, W. J., \& Russo, J. (2009). The longitudinal effects of depression on physical activity. General Hospital Psychiatry, 31(4), 306-315.

Schwartz, P., Periti, M., \& Malliani, P. (1975). Fundamentals of clinical cardiology: The long QT syndrome. American Heart Journal, 89, 378-390

Schwartz, P., Priori, S. G., Spazzolini, C., Moss, A. J., Vincent, G. M., Napolitano, C., et al. (2001). Genotype-phenotype correlation in the long-QT syndrome: Gene-specific triggers for life-threatening arrhythmias. Circulation, 103(1), 89-95.

Schwartz, P., Stramba-Badiale, M., Crotti, L., Pedrazzini, M., Besana, A., Bosi, G., et al. (2009). Prevalence of the congenital long-QT syndrome. Circulation, 120(18), 1761-1767.

Shanmugasegaram, S., Russell, K. L., Kovacs, A. H., Stewart, D. E., \& Grace, S. L. (2012). Gender and sex differences in prevalence of major depression in coronary artery disease patients: A meta-analysis. Maturitas, 73(4), 305-311.

Shields, M. (2006). Stress and depression in the employed population. Health Reports, 17(4), 11-29.

Stenson, P. D., Ball, E. V., Mort, M., Phillips, A. D., Shiel, J. A., Thomas, N. S., et al. (2003). Human Gene Mutation Database (HGMD): 2003 update. Human Mutation, 21(6), 577-581.

Stroud, L., Salovey, P., \& Epel, E. (2002). Sex differences in stress responses: Social rejection versus achievement stress. Biological Psychiatry, 52(4), 318-327.

van Langen, M., Hofman, N., Tan, H., \& Wilde, A. (2004). Family and population strategies for screening and counseling of inherited cardiac arrhythmias. Annals of Medicine, 36(Suppl I), $116-124$ 
Verbeek, D. E. P., van Riezen, J., de Boer, R. A., van Melle, J. P., \& de Jonge, P. (2011). A Review on the putative association between beta-blockers and depression. Heart Failure Clinics, 7(1), 89-99.

Viadero, M. T., Rubín, E., Amigo, T., \& González-Lamuño, D. (2011). Three generations of hereditary long-QT syndrome with complete penetrance caused by the p.G316E KCNQ1 mutation. Pediatric Cardiology, 32(1), 102-104.
Watkins, L. L., Blumenthal, J. A., Davidson, J. R. T., Babyak, M. A., McCants, C. B., \& Sketch, M. H. (2006). Phobic anxiety, depression, and risk of ventricular arrhythmias in patients with coronary heart disease. Psychosomatic Medicine, 68(5), 651-656.

Zimet, G., Dahlem, N., Zimet, S., \& Farley, G. (1988). The Multidimensional Scale of Perceived Social Support. Journal of Personality Assessment, 52, 30-41. 